\title{
Overexpression of a Chromatin Architecture-Controlling ATPG7 has Positive Effect on Yield Components in Transgenic Soybean
}

\author{
Hye Jeong $\mathrm{Kim}^{1 \dagger}$, Hyun Suk Cho ${ }^{1 \dagger}$, Jun Hun Pak ${ }^{1}$, Kook Jin Kim², Dong Hee Lee ${ }^{2}$, Young-Soo Chung * \\ ${ }^{1}$ Department of Molecular Genetics, College of Natural Resources and LifeScience, Dong-A University, Busan 49315, Korea \\ ${ }^{2}$ Genomine Advanced Biotechnology Research Institute, Genomine Inc., Pohang 37668, Korea
}

\begin{abstract}
AT-hook proteins of plant have shown to be involved in growth and development through the modification of chromatin architecture to co-regulate transcription of genes. Recently, many genes encoding AT-hook protein have been identified and their involvement in senescence delay is investigated. In this study, soybean transgenic plants overexpressing chromatin architecturecontrolling ATPG7 gene was produced by Agrobacterium-mediated transformation and investigated for the positive effect on the important agronomic traits mainly focusing on yield-related components. A total of 27 transgenic soybean plants were produced from about 400 explants. $T_{1}$ seeds were harvested from all transgenic plants. In the analysis of genomic DNAs from soybean transformants, ATPG7 and Bar fragments were amplified as expected, $975 \mathrm{bp}$ and $408 \mathrm{bp}$ in size, respectively. And also exact gene expression was confirmed by reverse transcriptase-PCR (RT-PCR) from transgenic line \#6, \#7 and \#8. In a field evaluation of yield components of $A T P G 7$ transgenic plants $\left(\mathrm{T}_{3}\right)$, higher plant height, more of pod number and greater average total seed weight were observed with statistical significance. The results of this study indicate that the introduction of $A T P G 7$ gene in soybean may have the positive effect on yield components.
\end{abstract}

Keywords Soybean, ATPG7, Agrobacterium-mediated transformation, Transgenic plants, Yield component

\section{INTRODUCTION}

AT-hook proteins of plant have shown to be involved in growth and development through the modification of chromatin architecture to co-regulate transcription of genes (Su et al. 2006; Lim et al. 2007; Street et al. 2008; Xiao et al. 2009). Many AT-hook motif proteins were identified from a variety of species such as Arabidopsis, maize and rice in plants (Li et al. 2002). The modulation of chromatin architecture is induced by genes controlling DNA methylation and histone acetylation/deactylation and functional genes of chromatin binding. This chromatin architecture plays an important role in growth and development in plants including meristem identity, leaf longevity and the development of flowering and seed formation ( $\mathrm{Su}$ et al.
2006; Lim et al. 2007; Street et al. 2008; Xiao et al. 2009).

Recently, many genes related to senescence delay have been identified in a research team of Genomine Inc. (data not shown). Several genes encoded for AT-hook binding proteins have been investigated for their function in chromatin remodeling and subsequent senescence delay in Arabidopsis (unpublished data). Functional change of Arabidopsis in morphology due to senescence delay resulted in increased biomass and yield.

Soybean (Glycine max [L.] Merr.), as a major crop, is important for the production of vegetable oil and protein in worldwide. Many reports point to the beneficial effects of soybean on human health and even as a source for medicines (Oksman-Caldentey and Hiltunen 1996; Zeng et al. 2004; Manavalan et al. 2009; John et al. 2016).

Received August 3, 2017; Revised August 20, 2017; Accepted August 20, 2017; Published September 1, 2017

*Corresponding author Young-Soo Chung, chungys@dau.ac.kr, Tel: +82-51-200-7510, Fax: +82-51-200-6536

${ }^{\dagger}$ These authors contributed equally. 
Soybean transformation has mostly been developed with Agrobacterium-mediated transformation (Hinchee et al. 1988), and improved rapidly by the use of half-seed explants (Paz et al. 2006). In our previous study (Kim et al. 2012), Soybean transformation efficiency was consistently improved with additional treatments such as addition of thiol compounds, sonication and vacuum. The improved efficiency made us enable to produce enough stable transgenic soybean plants with a few transformation trials. Ten to twenty healthy plants could be obtained from 300-400 seeds of explants. This improvement has substantial implication as a big forward step to functional genomics of soybean via transgenic research. With this modified transformation protocol, many genes have been introduced to soybean in order to investigate their physiological change or improvement in crops (Kim et al. 2013; Kim et al. 2016; Kim et al. 2017).

In this study, we generated soybean transgenic plants overexpressing chromatin architecture-controlling ATPG7 gene by Agrobacterium-mediated transformation and investigated the important agronomic traits mainly focusing on yield-related components.

\section{MATERIALS AND METHODS}

\section{Vector construction and Agrobacterium preparation}

ATPG7 (AT-hook protein of Genomine 7) gene (GenBank: DI237375.1) was provided by Dr. D.H. Lee (Genomine Inc., Korea) and was amplified by PCR using ATPG7-F primer (5'- ATGGATCCAGTACAATCTCATGGA-3') and ATPG7-R primer (5'- TCAATACGGTGGTCGTCCCGTTGA-3'). The desired destination vector, pCSEN (provided by Dr. D.H. Lee) was used for the vector construction. The plasmid, pCSEN-ATPG7 was constructed and transformed into Agrobacterium tumefaciens strain EHA105 (Karimi et al. 2002), following the protocol described by Kim et al. (2013, 2016, 2017).

\section{Soybean transformation}

Korean cultivar soybean seeds (Glycine max L. cv. Kwangankong) were utilized in Agrobacterium-mediated transformation experiments, following the protocol des- cribed by Kim et al. $(2013,2016,2017) . T_{0}$ plants with two trifoliates were screened using an herbicide assay to determine the resistance and to identify putative transformants that express Bar gene. The upper surface of a leaf was painted with $100 \mathrm{mg} / \mathrm{L}$ PPT using a brush. The response to the herbicide was observed at 3-5 days after PPT leaf painting. The PPT-resistant $\mathrm{T}_{0}$ plants were then grown in a greenhouse, and $\mathrm{T}_{1}$ seeds were harvested.

\section{Genomic DNA analysis of transgenic plants}

Total genomic DNA was extracted from leaf tissues of non-transgenic (NT) and $\mathrm{T}_{0}$ soybean plants using the cetyltrimethylammonium bromide. The polymerase chain reaction (PCR) was performed to detect the introduced genes with KOD FX polymerase (TOYOBO, Japan) according to the manufacturer's instructions, and two primer sets were designed to amplify regions of ATPG7 (5'-ATGGATCCAGTACAATCTCATGGA-3'/ $5^{\prime}$-TCAATACGGTGGTCGTCCCGTTGA-3') and Bar (5'-TCCGTACCGAGCCGCAGGAA-3'/5'-CCGGCAGGCTGAAGTCCAGC-3'). PCR was performed using KOD FX polymerase (TOYOBO, Osaka, Japan) according to the manufacturer's instructions.

\section{RNA analysis of transgenic plants}

Total RNAs were isolated from NT and $\mathrm{T}_{0}$ soybean plants using Plant RNA Purification Reagent (Invitrogen, USA) according to the manufacturer's instructions. Reverse transcriptase-PCR (RT-PCR) was performed using Maxime RT-PCR Premix (iNtRon, Korea) according to the manufacturer's instructions. The primer pairs used in the RT-PCR were as follows: ATPG7 forward, 5'-ATGGATCCAGTACAATCTCATGGA-3'/reverse, 5'-TCAATACGGTGGTCGTCCCGTTGA-3'; Bar forward, 5'TCCGTACCGAGCCGCAGGAA-3'/reverse, 5'-CCGGCAGGCTGAAGTCCAGC-3'. The constitutively expressed gene $T U B$ was used as a control and amplified using the primer set 5'-TGAGCAGTTCACGGCCATGCT-3'/5'-TCATCCTCGGCAGTGGCATCCT-3').

\section{Investigation of yield components in GMO field}

NT and transgenic soybean seeds ( $T_{3}$ generation) were planted in a seedling tray, and treated with $100 \mathrm{mg} / \mathrm{L} \mathrm{PPT}$ 
for the herbicide assay. Seedlings were then transplanted in GMO field (Keunwi, Kyungsangbukdo) in order to evaluate yield components including plant height, the number of branches per plant and the number of nodes per plant. Moreover, the number of pods per plant and the total seed weight were also determined to investigate the relative yield of transgenic plants.

\section{RESULTS}

\section{Production of transgenic soybean plants via Agrobacterium-mediated transformation}

To produce transgenic soybean plants with high-yield, the corresponding pCSEN-ATPG7 plasmid (Fig. 1) was used for the soybean transformation with half-seeds of the Korean soybean cultivar Kwangankong (Fig. 2) described by Kim et al. (2013, 2016, 2017). A total of 27 transgenic soybean plants were produced from about 400 explants. $T_{1}$ seeds were harvested from all transgenic plants. The whole procedure, starting from seed preparation to $T_{1}$ seed harvest, has taken about 6-7 months. Further generations were proceeded until $\mathrm{T}_{3}$ generation in GMO field (Keunwi, Kyungsangbukdo).

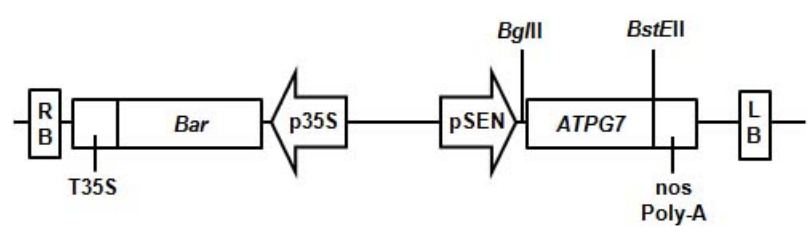

Fig. 1. Vector used for soybean transformation. Schematic representation of the vector pCSEN-ATPG7 containing $A T P G 7$ and Bar genes used for soybean transformation. The BglII and BstEII restriction enzyme sites are also marked. LB/RB: left/right T-DNA border sequences, p35S/T35S: CaMV (cauliflower mosaic virus) $35 \mathrm{~S}$ promoter/terminator, pSEN: stress-inducible promoter, Bar: coding region of the DL-phosphinothricin resistance gene.

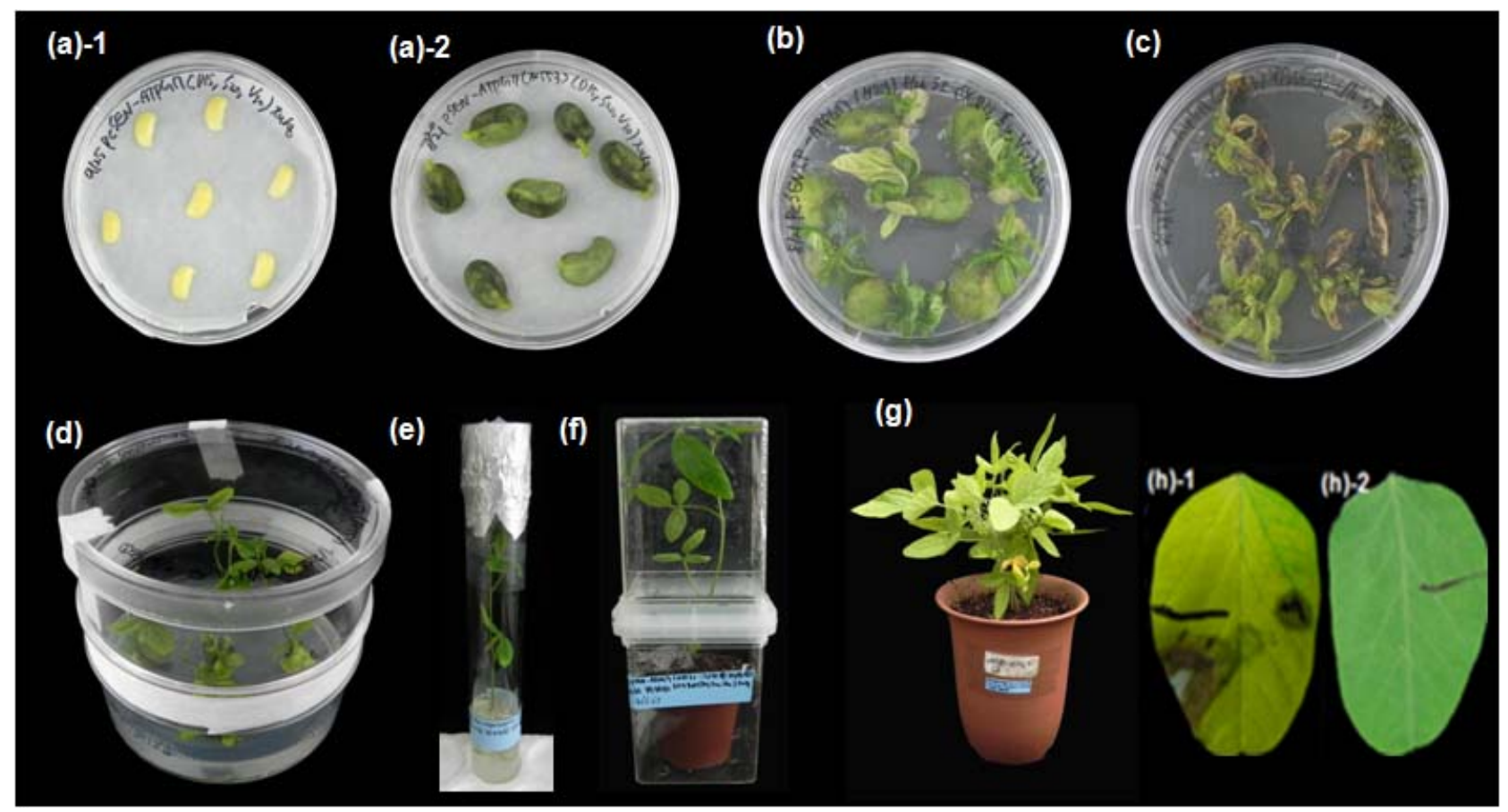

Fig. 2. Production of soybean transgenic plants with ATPG7 gene using Agrobacterium-mediated transformation. (a) Co-cultivation of half-seed explants after infection (left) and at five days after inoculation (right); (b) Shoot induction medium without PPT; (c) Shoot induction medium containing $10 \mathrm{mg} / \mathrm{L}$ PPT for Bar selection. (d) Shoot elongation medium containing $5 \mathrm{mg} / \mathrm{L} \mathrm{PPT}$; (e) Rooting medium; (f) Acclimation of putative transgenic plant in a small pot; (g) Transgenic plant $\left(\mathrm{T}_{0}\right)$ grown in a large pot in a greenhouse; (h) Leaf painting with herbicide $(100 \mathrm{mg} / \mathrm{L} \mathrm{PPT})$ to reveal the sensitivity of non-transgenic plant (left) and resistant of transgenic plant (right). 


\section{Analysis of transgene integration and expression}

To confirm the integration of the transgene in soybean transformants, genomic DNAs were isolated from $T_{0}$ transformants, and PCR was carried out to analyze the presence of ATPG7 and Bar genes, respectively (Data not shown). Only healthy and well-grown transgenic line \#6, $\# 7$ and \#8 were selected for the investigation of agronomic characteristics, and these lines were examined using PCR with $A T P G 7$ and Bar primers to amplify the DNA fragments of $975 \mathrm{bp}$ and $408 \mathrm{bp}$ in size, respectively (Fig. 3a). To analyze the transcript levels of $A T P G 7$ and Bar, reverse transcriptase-PCR (RT-PCR) was carried out with RNAs extracted from transgenic line \#6, \#7 and \#8. As shown in Fig. 3b, these genes were expressed in all 3 lines tested.

\section{Investigation of yield components in transgenic soybean}

To examine the yield components of ATPG7 transgenic

(a)

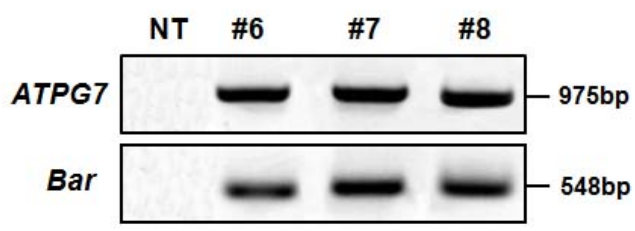

(b)

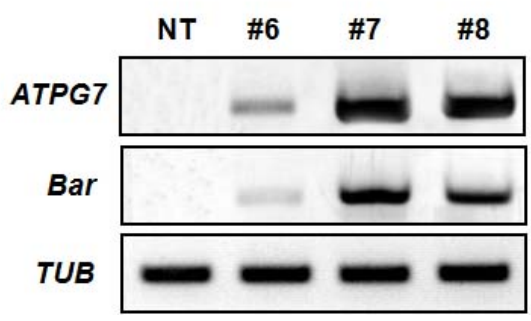

Fig. 3. Analysis of transgene integration and expression in ATPG7 transgenic plants $\left(\mathrm{T}_{0}\right)$. (a) Confirmation of introduced genes in $A T P G 7$ transgenic plants $\left(\mathrm{T}_{0}\right)$ using PCR. Genomic DNAs were extracted from $\mathrm{T}_{0}$ transgenic leaf tissues. (b) ATPG7 and Bar gene expression in $\mathrm{T}_{0}$ transgenic plants using reverse transcriptase-PCR (RT-PCR). Total RNAs were extracted from $T_{0}$ plants, and then analyzed by RT-PCR with the TUB gene as a quantitative control. NT: non-transgenic plant, \#6-8: ATPG7 transgenic lines $\left(\mathrm{T}_{0}\right)$. plants $\left(\mathrm{T}_{3}\right)$, we compared their agronomic characteristics to those of NT plants in GMO field. Agronomic traits including plant height, the number of nodes per plant, branches per plant, pods per plant and total seed weight of plants and transgenic lines (\#6, \#7 and \#8) were investigated (Fig. 4). The plant height of transgenic lines was similar to, or higher than NT plants. The number of pods in transgenic lines was more than those of NT plants, as showing about $16 \%, 38 \%$ and $40 \%$ increase in line $\# 6$, \#7 and $\# 8$, respectively. In total seed weight, transgenic line $\# 6, \# 7$ and $\# 8$ showed approximately $15 \%, 60 \%$ and $40 \%$ greater than non-transgenic plants with statistical significance $(P<0.05$ in line $\# 6$ and $P<0.01$ in line \#7 and \#8). This result is significantly related to the yield increase. Therefore, the important yield components of transgenic line \#6, \#7 and \#8 were more favorable for high yield than those of normal wild-type plants.

\section{DISCUSSION}

Relatively large number of stable transgenic plants was obtained in this experiment. We have been observed the transformation efficiency varied by different genes and constructs. The production of 27 plants out of 400 explants is relatively high frequency. The result might be from the additional treatments. Before we used the modified method, average efficiency of transformation was less than 3\% (unpublished data). Our Agrobacterium-mediated soybean transformation was primarily established based on the cotyledonary-node $(\mathrm{CN})$ method. Then half-seed method was mainly used for recent transformation experiment. The later method skipped the germination procedure of soybean seed on germination media. The biggest advantage of half-seed method is saving at least one week in the early procedure of transformation and no requirement for sophisticated wounding on explant. This modified protocol enabled us to produce the successful soybean transgenic plants with many genes (Kim et al. 2012; Kim et al. 2013, Kim et al. 2016; Kim et al. 2017).

Many chromatin architecture-controlling genes via senescence delay, which created phenotypic change including organ size of plants and yield components, have 
(a)

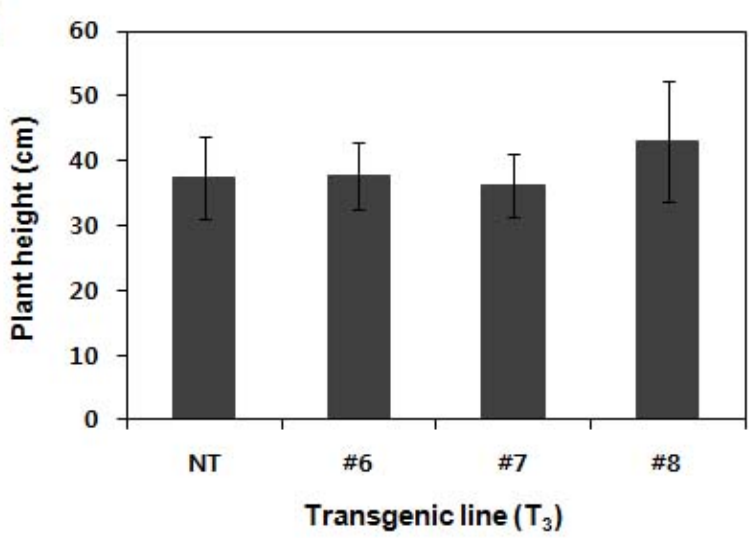

(c)

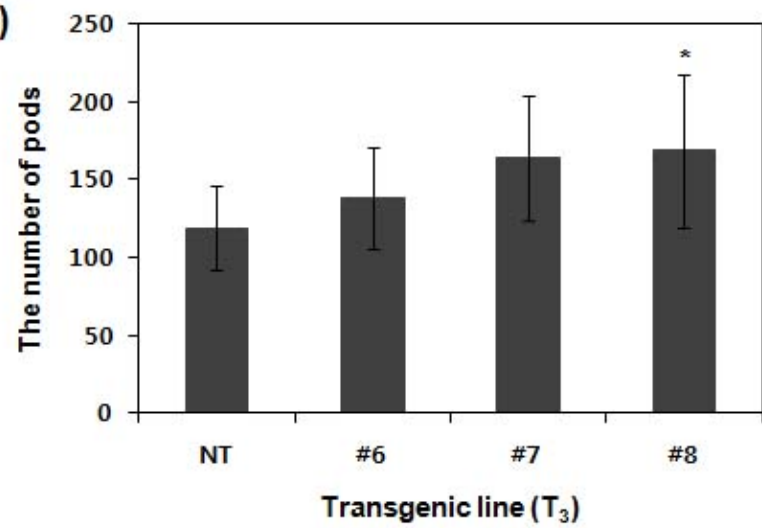

(b)

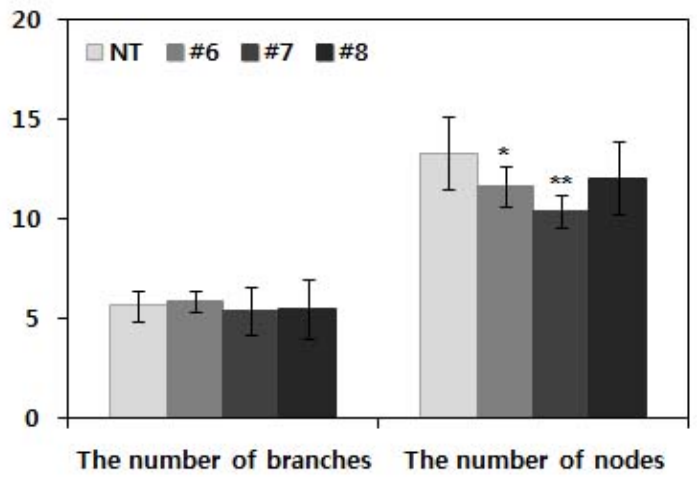

(d)

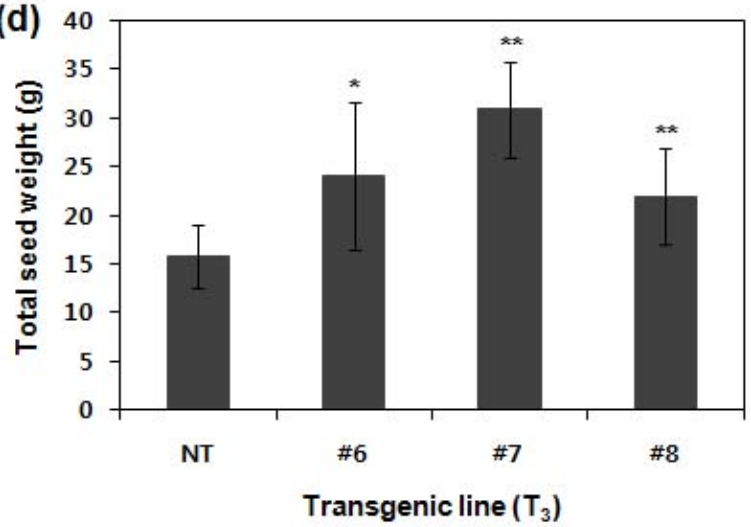

Fig. 4. Agronomic characteristics of $\mathrm{T}_{3}$ transgenic plants in GMO field. $\mathrm{NT}$ and $\mathrm{T}_{3} A T P G 7$ transgenic plants $(\mathrm{n}=20$ for each line) were grown in GMO field, and agronomic traits including plant height (a), the number of branches and nodes per plant (b), the number of pods per plant (c) and total seed weight (d) were investigated. Error bars indicate mean \pm standard deviation. Asterisks indicate significant changes compared with $\mathrm{NT}\left({ }^{*} P<0.05 ; * * P<0.01\right)$. NT: non-transgenic plants, \#6-8: ATPG7 transgenic lines $\left(\mathrm{T}_{0}\right)$.

been discovered by a research team of Genomine Inc. They obtained the result on the basic function of these genes with transgenic research in model plant, and hope to see similar result in crop like soybean. It may be too early to say the positive effect of those genes in the yield components of soybean with our limited results. Further generation should be evaluated for their yield-related main agronomic characters and connection with gene expression. The year of 2017, we have deployed next generation of 3 lines (\#6, $\# 7$ and \#8) to investigate the correlation between field performance of transgenic plants and gene expression at the cell level. The current result suggests that the overexpression of $A T P G 7$ gene in soybean contribute to the positive effect on yield components, indicating the modification of senescence could lead to yield increase.
Considering the daily accumulating new genes from genomic research, transgenic research based on highefficient transformation will have an important role in many respects. More active trial with transgenic crop should be carried with new candidate genes.

\section{ACKNOWLEDGEMENTS}

This work was supported by the Next-Generation BioGreen 21 Program (Code PJ011150), Rural Development Administration, and Korea Institute of Planning and Evaluation for Technology in Food, Agriculture, Forestry and Fisheries (Code 112124-5), Republic of Korea. 


\section{REFERENCES}

Hinchee MAW, Connor-Ward DV, Newell CA, McDonnell RE, Sato SJ, Gasser CS, et al. 1988. Production of transgenic soybean plants using Agrobacterium-mediated DNA transfer. Nat. Biotechnol. 6: 915-922.

John KMM, Natarajan S, Luthria DL. 2016. Metabolite changes in nine different soybean varieties grown under field and greenhouse conditions. Food Chem. 211: 347-355.

Karimi M, Inze' D, Depicker A. 2002. Gateway ${ }^{\mathrm{TM}}$ vectors for Agrobacterium-mediated plant transformation. Trends Plant Sci. 7: 193-195.

Kim HJ, Kim MJ, Pak JH, Im HH, Lee DH, Kim KH, et al. 2016. RNAi-mediated soybean mosaic virus (SMV) resistance of a Korean soybean cultivar. Plant Biotechnol. Rep. 10: 257-267.

Kim HJ, Kim MJ, Pak JH, Jung HW, Choi HK, Lee YH, et al. 2013. Characterization of SMV resistance of soybean produced by genetic transformation of $S M V-C P$ gene in RNAi. Plant Biotechnol. Rep. 7: 425-433.

Kim MJ, Kim HJ, Pak JH, Cho HS, Choi HK, Jung HW, et al. 2017. Overexpression of AtSZF2 from Arabidopsis showed enhanced tolerance to salt stress in soybean. Plant Breed. Biotech. 5: 1-15.

Kim MJ, Kim JK, Kim HJ, Pak JH, Lee JH, Kim DH, et al. 2012. Genetic modification of the soybean to enhance the $\beta$-carotene content through seed-specific expression. PLoS One 7: e48287.

Li G, Hall TC, Holmes-Davis R. 2002. Plant chromatin: development and gene control. BioEssays 24: 234-243.

Lim PO, Kim Y, Breeze E, Koo JC, Woo HR, Ryu JS, et al. 2007. Overexpression of a chromatin architecture-con- trolling AT-hook protein extends leaf longevity and increases the post-harvest storage life of plants. Plant $\mathrm{J}$. 52: $1140-1153$.

Manavalan LP, Guttikonda SK, Tran LSP, Nguyen HT. 2009. Physiological and molecular approaches to improve drought resistance in soybean. Plant Cell Physiol. 50: 1260-1276.

Oksman-Caldentey KM, Hiltunen R. 1996. Transgenic crops for improved pharmaceutical products. Field Crops Res. 45: 57-69.

Paz MM, Martinez JC, Kalvig AB, Fonger TM, Wang K. 2006. Improved cotyledonary node method using an alternative explant derived from mature seed for efficient Agrobacterium-mediated soybean transformation. Plant Cell Rep. 25: 206-213.

Sreet IH, Shah PK, Smith AM, Avery N, Neff MM. 2008. The AT-hook-containing proteins SOB3/AHL29 and ESC/ AHL27 are negative modulators of hypocotyl growth in Arabidopsis. Plant J. 54: 1-14.

Su Y, Kwon CS, Bezhani S, Huvermann B, Chen C, Peragine A, et al. 2006. The N-terminal ATPase AT-hook-containing region of the Arabidopsis chromatin-remodeling prtein SPLAYED is sufficient for biological activity. Plant J. 46: 685-699.

Xiao C, Chen F, Yu X, Lin C, Fu YF. 2009. Over-expression of an AT-hook gene, AHL22, delays flowering and inhibits the elongation of the hypocotyl in Arabidopis thaliana. Plant Mol. Biol. 71: 39-50.

Zeng P, Vadnais DA, Zhang Z, Polacco JC. 2004. Refined glufosinate selection in Agrobacterium-mediated transformation of soybean [Glycine $\max (\mathrm{L}$.$) Merrill]. Plant$ Cell Rep. 22: 478-482. 